\title{
Analisis Sistem Antrian dalam Meningkatkan Pelayanan Customer Di PT. Optima Kurnia Elok Menggunakan Promodel
}

\author{
Novia Atdha Viana ${ }^{1}$, Asep Endih Nurhidayat ${ }^{2}$ \\ ${ }^{1,2}$ Program Studi Teknik Industri, Universitas Indraprasta PGRI, Jakarta \\ 1noviaatdhaviana@gmail.com, ${ }^{2}$ aennoerhidayat@gmail.com
}

\begin{abstract}
Abstrak - PT. Optima Kurnia Elok adalah salah satu perusahaan ritel yang bergerak di bidang percetakan yang memiliki 3 loket pelayanan. Permasalahan yang terjadi pada perusahaan ini adalah waktu pelayanan yang lama. Tujuan penelitian ini untuk mengetahui system antrian loket kedatangan sudah efektif atau belum. Penelitian dilakukan pada pada tanggal 22 Agustus 2018 dengan jumlah customer sebanyak 25 orang, tanggal 30 Agustus 2018 dengan jumlah customer sebanyak 23 orang, tanggal 01 September 2018 dengan jumlah customer sebanyak 24 orang dan tanggal 07 September 2018 dengan jumlah customer sebanyak 23 orang. Data yang diambil pada penelitian ini berupa jumlah kedatangan dan waktu pelayanan. Dalam penelitian ini dipilih aplikasi promodel untuk membuat simulasi system antrian. Berdasarkan hasil penelitian system antrian pada perusahaan ini masih belum efektif dilihat dari fasilitas pelayanan selama 4 hari penelitian utilisasi terendah pada loket 3 sebesar 33,34\% sehingga pada loket ini perlu ditingkatkan lagi pelayanannya. Aktifitas kerja tertinggi terdapat pada loket 1 dengan rata-rata 49,67\% atau 59,60 menit sedangkan idle terbesar ada di bagian loket 3 dengan ratarata $66,76 \%$ atau 80,11 menit. Dan untuk 1 customer rata-rata waktu dalam systemnya sebesar 12,59 menit dengan waktu tunggu sebesar 6,8 menit, waktu oprasi sebesar 7,45 menit dan waktu hambatan sebesar 1,04 menit.
\end{abstract}

Kata kunci-Simulasi, Promodel, Antrian.

\begin{abstract}
PT. Optima Kurnia Elegant is one of the retail companies engaged in the printing that has 3 service counters. The problems that occur in this company are long service time. The purpose of this research to know the system of queuing of arrival counters has been effective. The research was conducted on 22 August 2018 with the number of customers as much as 25 people, 30 August 2018 with the number of customers as much as 23 people, dated 01 September 2018 with the number of customers as much as 24 people and the date of 07 September 2018 With a total of 23 customers. The Data taken in this research form the number of arrivals and service time. In this research selected application Promodel to create a simulated queuing system. Based on the results of the research queue system in this company is still not effectively seen from the service facilities for 4 days the lowest utilization research at counter 3 of $33.34 \%$ so that the counter needs to be improved again. The highest working activity is at counter 1 with an average of $49.67 \%$ or 59.60 minutes while the largest idle is at the counter 3 with an average of $66.76 \%$ or 80.11 minutes. And for 1 customer the average time in the system is 12.59 minutes with a waiting time of 6, 8 minutes, the time of the option of 7, 45min and the resistance time of 1.04 minutes.
\end{abstract}

Keywords - Simulation, Promodel, Queue.

\section{Pendahuluan}

$\mathrm{D}$ i era globalisasi saat ini dunia industri berkembang sangat pesat baik industri jasa maupun industri produk dalam hal ini waktu merupakan hal yang sangat penting terlebih lagi bagi perusahaan penyedia jasa, maka dari itu perusahaan harus dapat mempertahankan eksistensinya dengan cara membatasi waktu pelayanan sehingga perusahaan dapat memenuhi target banyaknya pelayanan pada customer. Antrian dapat ditemukan pada beberapa fasilitas pelayanan umum dimana masyarakat atau barang akan mengalami proses antrian dari mulai proses kedatangan, memasuki antrian dan menunggu, hingga proses pelayanan berlangsung sampai pada berakhirnya pelayanan [1].

PT. Optima Kurnia Elok adalah salah satu perusahaan ritel yang bergerak di bidang percetakan yang memiliki menerapak sistem produksi make to order dengan fasilitas 3 loket pelayanan dan memproduksi barang-barang dengan bahan baku yang kualitasnya sesuai pemesanan dan bahan yang digunakan juga akan sesuai dengan pesanan.Permasalahan yang sering terjadi pada perusahaan ini adalah waktu pelayanan yang lama dan kurang efektifnya pelayanan yang menyebabkan terjadinya antrian. Dengan menggunaka simulasi promodel ini bertujuan menganalisis loket antrian apakah sudah efektif atau belum. Tingkat kepuasan pelanggan pada layanan menggunakan model antrian multichanel dengan kedatangan Poisson dan waktu layanan eksponensial [2].

Antrian adalah ilmu pengetahuan tentang bentuk antrian dan merupakan orang-orang atau barang dalam barisan yang sedang menunggu untuk dilayani atau meliputi bagaimana perusahaan dapat menentukan waktu dan fasilitas yang sebaik-baiknya agar dapat melayani Customer dengan efisien [3]. Tujuan dari analisis antrian adalah untuk meminimalkan Customer menunggu dan layanan biaya kapasitas. Dengan ini, para manajer mencoba menciptakan keseimbangan antara penggunaan secara efisien sumber daya dan menjaga kepuasan Customer tetap tinggi [4]. Ada 4 struktur antrian : single channel single server, single channel multi server, multi channel single server,multi channel multi server [5].

Model adalah representasi dari sistem nyata yang disederhanakan. model merupakan alat yang sangat berguna untuk menganalisis maupun merancang sistem [6]. Simulasi 
adalah suatu metodologi untuk melaksanakan percobaan dengan menggunakan model dari suatu sistem nyata [7]. Dengan membuat model simulasi dari suatu sistem maka diharapkan dapat lebih mudah untuk melakukan analisis.

Promodel singkatan dari Production Modeler adalah sebuah aplikasi yang dikeluarkan oleh perusahaan Promodel. Aplikasi ini berfungsi untuk mensimulasikan atau memodelkan berbagai jenis sistem manufaktur dan pelayanan. Sistem manufaktur tersebut seperti job shop,conveyors, perakitan, sistem just-in-time, sistem manufaktur yang fleksibel itu semua bisa dimodelkan dengan promodel [8]. Model merupakan bentuk sederhana dari sebuah sistem. Sistem disini bisa berupa sistem dalam pelayanan umum atau proses manufaktur. Untuk bisa mensimulasikan dalam program promodel maka kira membuat model yang merupakan gambaran sistem tersebut [9]. Dalam ProModel 6.0 disediakan suatu fasilitas yang disebut dengan Stat::Fit. Stat::Fit adalah suatu aplikasi statistik yang digunakan untuk menentukan model statistik yang akan digunakan sebagai input simulasi menggunakan ProModel [10].

\section{Metode PENELITIAN}

Penelitian dilaksanakan di PT. Optima Kurnia Elok pukul14.00 WIB sampai dengan pukul16.00 WIB. Metode penelitian yang digunakan penelitian deskriptif observasional dengan pengamatan langsung terhadap sistem antrian yang ada di PT. Optima Kurnia Elok dalam upaya mengetahui kinerja sistem antrian yang ada disana, setelah mengidentifikasi masalah yang ada, langkah selanjutnya peneliti melakukan studi pustaka untuk memecahkan masalah yang ada yaitu dengan cara mencari metode yang sesuai untuk melakukan pengolahan data. Dalam menyelesaikan permasalahan dalam penelitian menggunakan software ProModel dan Stat::Fit.

1. Langkah-langkah membukasoftware ProModel adalah: [11]

a. Pertama-tama kita buka program Promodel dengan cara mengklik menu Start kemudian All Program dan selanjutnya pilih Promodel.

b. Selanjutnya untuk membuat model simulasi yang baru, pilih menu File, New kemudian akan tampil General Information Window. pada bagian Title diisi dengan judul model yang diinginkan. Pada bagian Time Unit dan Distance Unit diisi dengan satuan jarak dan waktu yang kita inginkan. Selanjutnya kita pilih Graphic Library yang sesuai dengan simulasi yang digunakan.

c. Membuat location yaitu tempat dilakukan proses entitas dalam sistem.

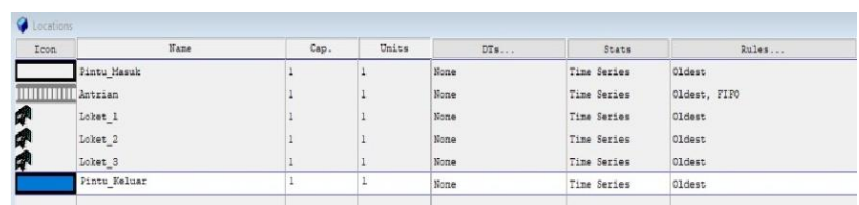

Gambar 1. Location

d. Membuat entities yang dimaksud dalam hal ini adalah customer yang diproses di dalam sistem.

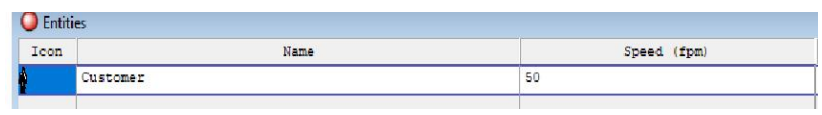

Gambar 2. Entities

e. Membuat arrival yaitu kedatangan entitas yang dijadwalkan untuk tiba dalam sistem.

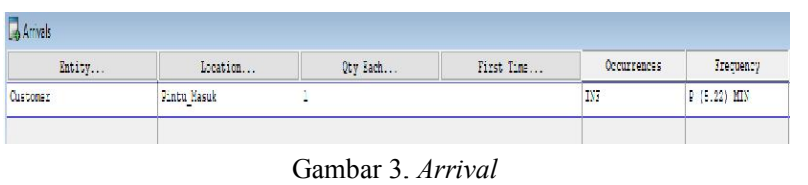

f. Membuat process yaitu rute dari entities dalam sistem dan operasi yang mengambil tempat lokasi yang dimasukinya.

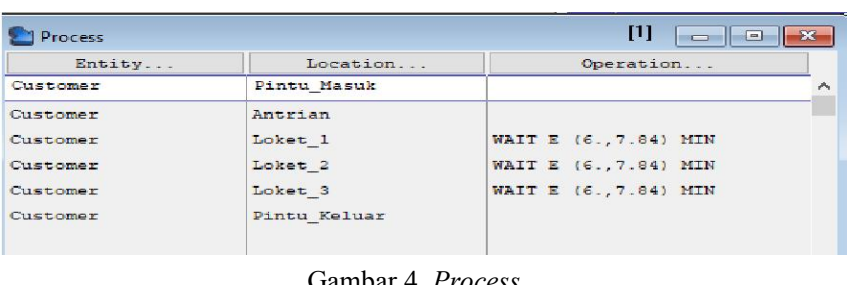

Gambar 4. Process

2. Langkah-langkah menggunakan Stat::Fit adalah: [12]

a. Buka program ProModel, kemudian pilih pada toolbox ProModel : Tools Stat::Fit

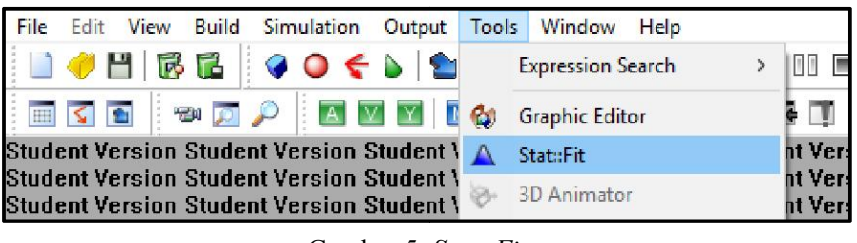

Gambar 5. Stat::Fit

b. Setelah fasilitas Stat::Fit tersedia, langkah selanjutnya pilih menu : File-New. Kemudian akan tersedia lembar kerja baru.

Gambar 9. Layout Penelitian

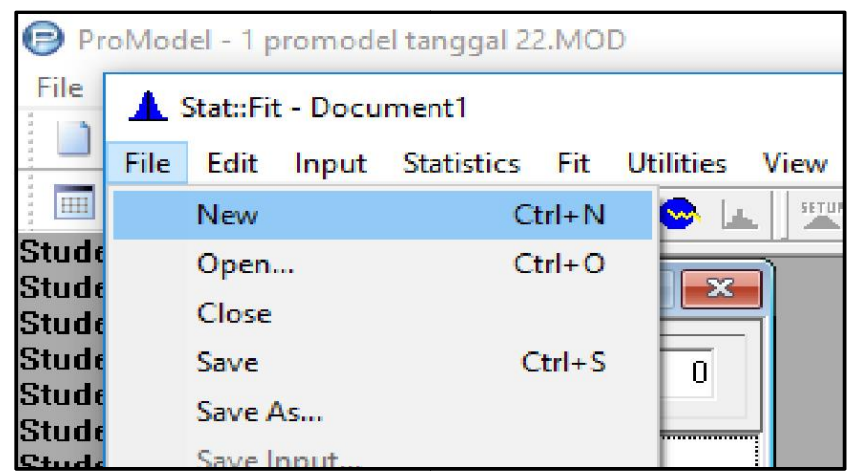

\section{HASIL DAN PEMBAHASAN}

Untuk mendapatkan data yang dibutuhkan, dilakukan pengamatan yang dilaksanakan pada PT. Optima Kuria Elok dimulai dari pukul 14.00 WIB sampai dengan pukul 16.00 WIB selama 4 hari dengan jumlah server 3 loket. Dibawah ini adalah gambar layout tempat pengamatan yang akan dilakukan analisis data dan simulasi menggunakan promodel. 


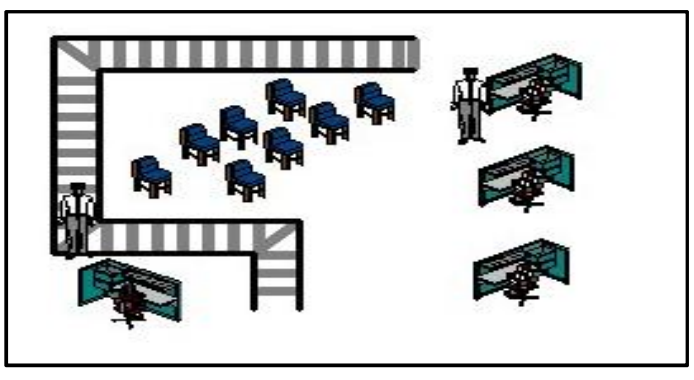

Gambar 9. Layout Penelitian

Dari pengamatan tersebut diperoleh data rata-rata kedatangandan rata-ratapelayanan.

Tabel 1. Data Pengamatan

\begin{tabular}{clccc}
\hline No & \multicolumn{1}{c}{ Hari/Tanggal } & $\begin{array}{c}\text { Kedatangan } \\
\text { Customer }\end{array}$ & $\lambda$ & $\mu$ \\
\hline 1 & Rabu, 22 Agustus 2018 & 25 & 12,5 & 4,68 \\
2 & Kamis, 30 Agustus 2018 & 23 & 11,5 & 5,34 \\
3 & Sabtu, 1 September 2018 & 24 & 12 & 4,74 \\
4 & Jumat, 7 September 2018 & 23 & 11,5 & 4,32 \\
\hline
\end{tabular}

Dari tabel 1 diketahui lamda $(\lambda)$ dan $(\mu)$ nya sehingga dapat ditentukan distribusi menggunakan stat::fit pada software promodel.

Tabel 2. Tabel Pemilihan Distibusi Data Kedatangan

\begin{tabular}{clcll}
\hline Waktu & Hasil Stat::fit & Rank & Acceptance & $\begin{array}{c}\text { Distibusi } \\
\text { Pilihan }\end{array}$ \\
\hline 22/08/18 & Poisson(4.72) & 100 & do not reject & Poisson \\
30/08/18 & Poisson(5.7) & 100 & do not reject & Poisson \\
01/09/18 & Poisson(5.38) & 100 & do not reject & Poisson \\
07/09/18 & Poisson(5.26) & 100 & do not reject & Poisson \\
\hline
\end{tabular}

Dari tabel 2 dapat diketahui bahwa tingkat kedatangan pada PT Optima Kurnia Elok ini berdistribusi poisson.

Tabel 3. Tabel Pemilihan Distibusi Data Pelayanan

\begin{tabular}{clccc}
\hline Waktu & \multicolumn{1}{c}{ Hasil Stat::fit } & Rank & Acceptance & $\begin{array}{c}\text { Distibusi } \\
\text { Pilihan }\end{array}$ \\
\hline \multirow{2}{*}{$22 / 08 / 18$} & Lognormal(5.,1.53,1.28) & 79,4 & do not reject & \\
& Eksponential(5,7.89) & 70 & do not reject & Lognormal \\
& Uniform(5,35) & 0 & Reject & \\
& Lognormal(6.,1.51,0.676) & 100 & do not reject & \\
30/08/18 & Eksponential(6.,5.58) & 5,89 & do not reject & Lognormal \\
& Uniform(6.,32.) & 0 & Reject & \\
& Lognormal(7.,1.56,0.756) & 100 & do not reject & \\
$01 / 09 / 18$ & Eksponential(7.,59) & 29,1 & do not reject & Lognormal \\
& Uniform(7.,22.1) & 1,84 & do not reject & \\
& Lognormal(6.,1.87,0.654) & 100 & do not reject & \\
$07 / 08 / 18$ & Eksponential(6.,7.84) & 74,98 & do not reject & Lognormal \\
& Uniform(6.,26) & 0 & reject & \\
\hline
\end{tabular}

Dari Tabel 3 dapat diketahui bahwa tingkat pelayanan pada PT Optima Kurnia Elok ini berdistribusi lognormal. Dapat diliha dari rank karena semakin tinggi rank maka distribusi tersebut semakin baik dalam mewakili data yang kita milik.

Hasil output simulasi yang dijalankan menggunakan aplikasi Promodel sebagai berikut.

1. Utilisasi

\begin{tabular}{lccccc}
\multicolumn{5}{c}{ Tabel 4. Tabel Utilisasi } \\
\hline \multirow{2}{*}{ Name } & $\begin{array}{c}\text { 22/08/18 } \\
\text { \%Utilization }\end{array}$ & $\begin{array}{c}\text { \% } \\
\text { \%Utilization }\end{array}$ & \%Utilization & \%Utilization & Rata \% \\
\hline Loket_1 & 56,98 & 45,75 & 44,52 & 51,41 & 49,67 \\
Loket_2 & 52,60 & 43,87 & 33,15 & 32,67 & 40,57 \\
Loket_3 & 43,84 & 27,42 & 33,47 & 28,23 & 33,24 \\
\hline
\end{tabular}

Dari hasil utilisasi pada tabel 4 loket pelayanan memiliki tingkat utiliasi loket yang rendah hampir tidak mencapai $50 \%$ sehingga tingkat pelayanan dinilai kurang memuaskan dan memiliki batas pengendalian yang kurang baik. Sehingga perlu adanya perbaikan pelayanan pada sistem antrian sehingga utilisasi meningkat dan tingkat pelayanan customer pun bertambah yang dapat dirasakan semaksimal mungkin.

\section{Location Single}

\begin{tabular}{ccccccc} 
& \multicolumn{7}{c}{ Tabel 5. Tabel Location Single } \\
\hline \multirow{2}{*}{ Tanggal } & Loket & Loket & Loket & Loket & Loket & Loket \\
& 1 & 2 & 3 & 1 & 2 & 3 \\
\hline $22 / 08 / 18$ & 56,99 & 52,6 & 43,83 & 43,01 & 47,4 & 56,17 \\
\hline $30 / 08 / 18$ & 45,75 & 43,87 & 27,42 & 54,25 & 56,13 & 72,58 \\
\hline $01 / 09 / 18$ & 44,51 & 33,15 & 33,47 & 55,49 & 66,85 & 66,53 \\
\hline $07 / 09 / 18$ & 51,42 & 32,67 & 28,23 & 48,58 & 67,33 & 71,77 \\
\hline Rata-rata & 49,67 & 40,57 & 33,24 & 50,33 & 59,43 & 66,76 \\
\hline
\end{tabular}

Aktifitas kerja tertinggi terdapat pada loket 1 dengan rata-rata 49,67\% atau 59,60 menit, dengan persentase kerja tertinggi pada tanggal 22 Agustus 2018 sebesar $56,99 \%$ atau 68,38 menit dan aktifitas kerja terendah terdapat pada loket 3 dengan rata-rata $33,24 \%$ atau 40,28 menit, dengan persentase kerja terendah pada tanggal 30 Agustus 2018 sebesar 27,42\% atau 33 menit.

Waktu idle tertinggi terdapat pada loket 3 dengan ratarata idle $66,76 \%$ atau 80,11 menit dari ke 4 hari penelitian pada tanggal 30 Agustus 2018 ini fasilitas pelayanan kurang optimal dengan rata-rata persentasi idle 72,58\% Sedangkan pada tanggal 22 Agustus 2018 waktu idle rendah hal ini membuat fasilitas pelayanan sudah optimal dengan rata-rata persentasi idle 43,01\%. Semakin besar waktu idle, maka semakin kurang optimal pemanfaatan pada loket.

\section{Entity Activity}

\begin{tabular}{llccccc}
\multicolumn{7}{c}{ Tabel 6 Tabel Entity Activity } \\
\hline Tanggal & Name & $\begin{array}{c}\text { Total } \\
\text { Entries }\end{array}$ & $\begin{array}{c}\text { Avg Time } \\
\text { In System } \\
(\text { MIN) }\end{array}$ & $\begin{array}{c}\text { Waiting } \\
\text { (MIN) }\end{array}$ & $\begin{array}{c}\text { Avg Time In Avg Time } \\
\text { Operation } \\
(\text { MIN) }\end{array}$ & $\begin{array}{c}\text { In Blocked } \\
\text { (MIN) }\end{array}$ \\
\hline $22 / 08 / 18$ & Customer & 25 & 10,62 & 5,01 & 8,63 & 0,17 \\
$30 / 08 / 18$ & Customer & 23 & 13,13 & 4,54 & 7,32 & 0,82 \\
$01 / 09 / 18$ & Customer & 24 & 16,53 & 9,42 & 6,98 & 2,55 \\
$07 / 09 / 18$ & Customer & 23 & 10,09 & 8,23 & 6,85 & 0,63 \\
\hline
\end{tabular}

Berdasarkan tabel 6 maka dapat diketahui aktivitas mana yang paling lama yaitu tanggal 01 September 2018 dengan jumlah customer yang datang berjumlah 24 orang pelanggan. Dengan rata-rata waktu customer didalam sistem yaitu 16,53 menit dan rata-rata waktu tunggu 9,42 Menit. Dan dari ke 4 hari penelitian rata-rata waktu dalam sistemnya sebesar 12,59 menit dengan waktu tunggu 6,8 menit, waktu oprasi 7,45 menit dan waktu hambatan sebesar 1,04 menit.

\section{SIMPULAN}

Model/jenis antrian yang digunakan di PT Ooptima Kurnia Elok adalah jenis antrian Multi Channel Single Server dengan menerapkan disiplin antrian yaitu First In First Out (FIFO) dengan pola kedatangan customer berdistribusi Poisson dan pola pelayanan tidak berdistribusi eksponensial.Sistem antrian di PT. Optima Kurnia Elok masih belum efektif, karena idle di bagian loket 3 masih sangat besar dengan rata-rata $66,76 \%$ atau 80,11 menit serta tingkat utilitas loket yang rendah hampir tidak mencapai 
50\% sehingga tingkat pelayanan dinilai kurang memuaskan dan memiliki batas pengendalian yang kurang baik. Aktifitas kerja tertinggi terdapat pada loket 1 dengan ratarata 49,67\% atau 59,60 menit sedangkan idle terbesar ada di bagian loket 3 dengan rata-rata $66,76 \%$ atau 80,11 menit. Dan untuk 1 customer rata-rata waktu dalam sistemnya sebesar 12,59 menit dengan waktu tunggu sebesar 6,8 menit, waktu oprasi sebesar 7,45 menit dan waktu hambatan sebesar 1,04 menit.

\section{REFERENSI}

[1] Siswanto. Operations Research Jilid 2. Jakarta : Erlangga. 2007.

[2] E. Berhan, Bank Service Performance Improvements using Multi-Sever Queue System. IOSR Journal of Business and Management (IOSR-JBM), 17, 65-69. 2015.

[3] M. Maeflinda, Operations Research (RisetOperasi).UR PRESS: Pekanbaru. 2011.

[4] R. Ginting, Statistika Teknik Industi. Jakarta: Erlangga. 2007.

[5] J. Heizer, dan B. Render, Manajemen Operasi. Jakarta: Salemba Empat. 2011.

[6] D. S. Goldstein, Improved Customer Satisfaction Through Dedicated Service Channel. Journal of Applied Business and Economics, 5, 1-34. 2009.

[7] M. Arifin, Simulasi Sistem Industri.Yogyakarta: Graha Ilmu. 2009.

[8] Asmungi. Simulasi Komputer Sistem Diskrit. Yogyakarta: Andi. 2007. 